\title{
Stereoselective synthesis with and without organometallics
}

\author{
Léon Ghosez \\ Laboratoire de Chimie organique de Synthèse, Université catholique de Louvain \\ place Louis Pasteur, 1, B - 1348 Louvain-la-Neuve, Belgium
}

\begin{abstract}
The first part of this paper deals with stereochemical studies related to the DielsAlder reactions of 2-azadienes. 2-Azadienes could be readily prepared from carboxylic acid chlorides and imine derivatives. Their reactions with electron-poor dienophiles showed an interesting chemical dichotomy : cyclic dienophiles mainly yielded endo-adducts while acyclic dienophiles reacted with a high exo-selectivity. This selectivity could be further increased by using Lewis acids which are compatible with the reactive azadienes. Highly selective asymmetric cycloadditions were observed with unsaturated amides derived from $\mathrm{C}_{2}$ symmetric pyrrolidines. Less satisfactory results were obtained with Evans' and Oppolzer's dienophiles. The second part deals with stereoselective cyclopentannulations of enones. It is shown that a three-carbon reagent bearing an orthoester at $C_{1}$ and a sulphone at $C_{2}$ reacts as a 1,3-dipole equivalent with enones to give a cyclopentannulation product. The reaction is general and of great synthetic value. Our efforts to develop an asymmetric version of this reaction have been successful : racemic sulphonamide-orthoesters have been shown to effect the cyclopentannulation of cyclic enones with high facial selectivity.
\end{abstract}

\section{Introduction}

Cycloaddition and cyclocondensation reactions are of great value for the construction of carbo- and heterocycles. They make a maximum use of the atomic content of the reaction partners (high atom economy). 1 This lecture deals with stereochemical studies related to two representatives of these classes of reactions.

\section{Stereoselective cycloadditions with $\mathbf{2}$-azadienes.}

Earlier studies from our laboratory had shown that a reactive class of 2-azadienes could be readily prepared from carboxylic acid chlorides and imine derivatives (Scheme 1).2

Scheme 1

1.<smiles>[X]/C=N\[R16]</smiles>

$X=i-P r O, t B u M e_{2} S i O$, Aryl, tBu

$\mathrm{R}^{1}=\mathrm{H}$, Alkyl, Aryl, Alkenyl, $\mathrm{F}, \mathrm{Cl}$

$\mathrm{R}^{2}=\mathrm{Me}, \mathrm{tBu}$

2.

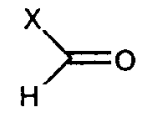

$$
\underset{\text { 2. } \mathrm{Et}_{3} \mathrm{~N}, \mathrm{R}^{1} \mathrm{CH}_{2} \mathrm{COCl}}{\longrightarrow}
$$

$\mathrm{X}=\mathrm{Aryl}, \mathrm{tBu}, \mathrm{i}-\mathrm{Pr}, \mathrm{CH}=\mathrm{CH} \cdot \mathrm{R}$

$\mathbf{R}^{1}=\mathrm{H}$, Alkyl, Aryl, Alkenyl<smiles></smiles>

(25 examples)<smiles>[X]C=NC(=C[R])O[SiH3]</smiles>

(10 examples) 
This convergent strategy allowed the preparation of a wide variety of 2-azadienes. These are useful reagents for the synthesis of pyridones, isoquinolones and pyrimidones with defined substitution pattern. 3

Cycloadditions of 2-azadienes with electron-deficient olefins showed an unexpected stereochemical dichotomy. 4,5,6 Reactions with cyclic dienophiles took place with the expected endo-selectivity (Scheme 2). The stereochemical outcome of the reactions with acyclic dienophiles was surprisingly different : a high kinetic exo-selectivity was observed in all cases.

Scheme 2

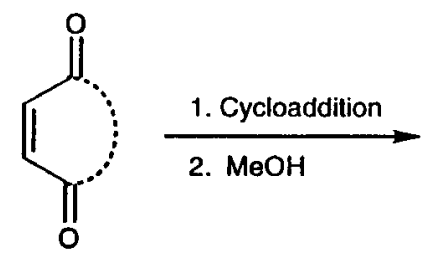

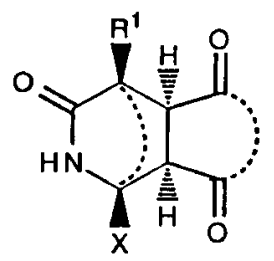

Endo (80-100\% selectivity)

$$
\begin{aligned}
& Z=\mathrm{CN}, \mathrm{CO}_{2} \mathrm{Me}, \mathrm{CONR}_{2}, \mathrm{COCH}_{3} \\
& \mathrm{R}^{3}=\mathrm{H}, \mathrm{CH}_{3}, \text { Aryl, } \mathrm{CO}_{2} \mathrm{Me}
\end{aligned}
$$<smiles>[Z]C1NC(=O)C([2H])([2H])[C@H]([Z])[C@H]1[2H]</smiles>

Exo ( $79-100 \%$ selectivity)

We assigned this unusual stereochemical dichotomy to different reacting conformations (Scheme 3). Cyclic dienophiles which are constrained in a s-trans conformation would prefer an endo-transition state stabilised by secondary molecular orbital interactions and not suffering from electrostatic repulsions between the oxygen lone pairs and the gross orbital charge on nitrogen.7 The corresponding exo-transition state would not benefit from the stabilising molecular orbital interactions.

Scheme 3

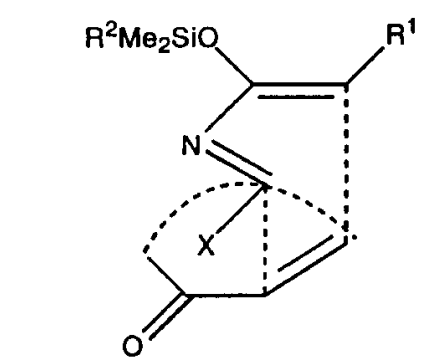

ENDO - TS for $s$ - trans conformer of cyclic dienophiles

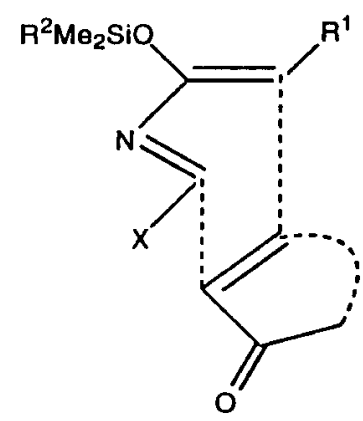

EXO - TS for S - trans conformer of cyclic dienophiles

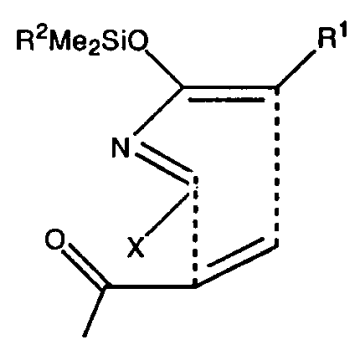

ENDO - TS for $s$ - cis conformer of acyclic dienophiles

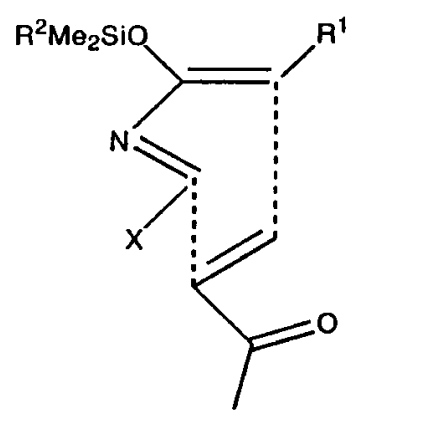

EXO - TS for s - cis contormer of acyclic dienophiles 
Acyclic dienophiles such as amides $\left(\mathrm{Z}=\mathrm{CONR}_{2}\right)$ and ketones $\left(\mathrm{Z}=\mathrm{COCH}_{3}\right)$ would react in their $s$-cis conformations. In this case the stabilisation provided by the secondary molecular orbital interactions would be overcome by destabilising electrostatic repulsions since the carbonyl oxygen would be closer to the nitrogen of the diene. These destabilising interactions do not exist in the corresponding exo-transition state which is thus preferred. This explanation does not take steric effects into account although, in many cases, they could overcome electronic factors.

Since electrostatic repulsions had been invoked as destabilising factors for the ENDO-TS resulting from the s-cis dienophile, we anticipated that the replacement of the $\mathrm{C}=\mathrm{O}$ group by a positively charged substituent would lower the energy of the ENDO-TS since electrostatic repulsions would be replaced by coulombic attractions. In principle this could be achieved by running the cycloaddition in the presence of a Lewis acid. However, in many cases, the presence of Lewis acids led to the decomposition of the highly reactive azadiene, even when a very nucleophilic carbonyl group was used (e.g. an amide , Scheme 4).5,6

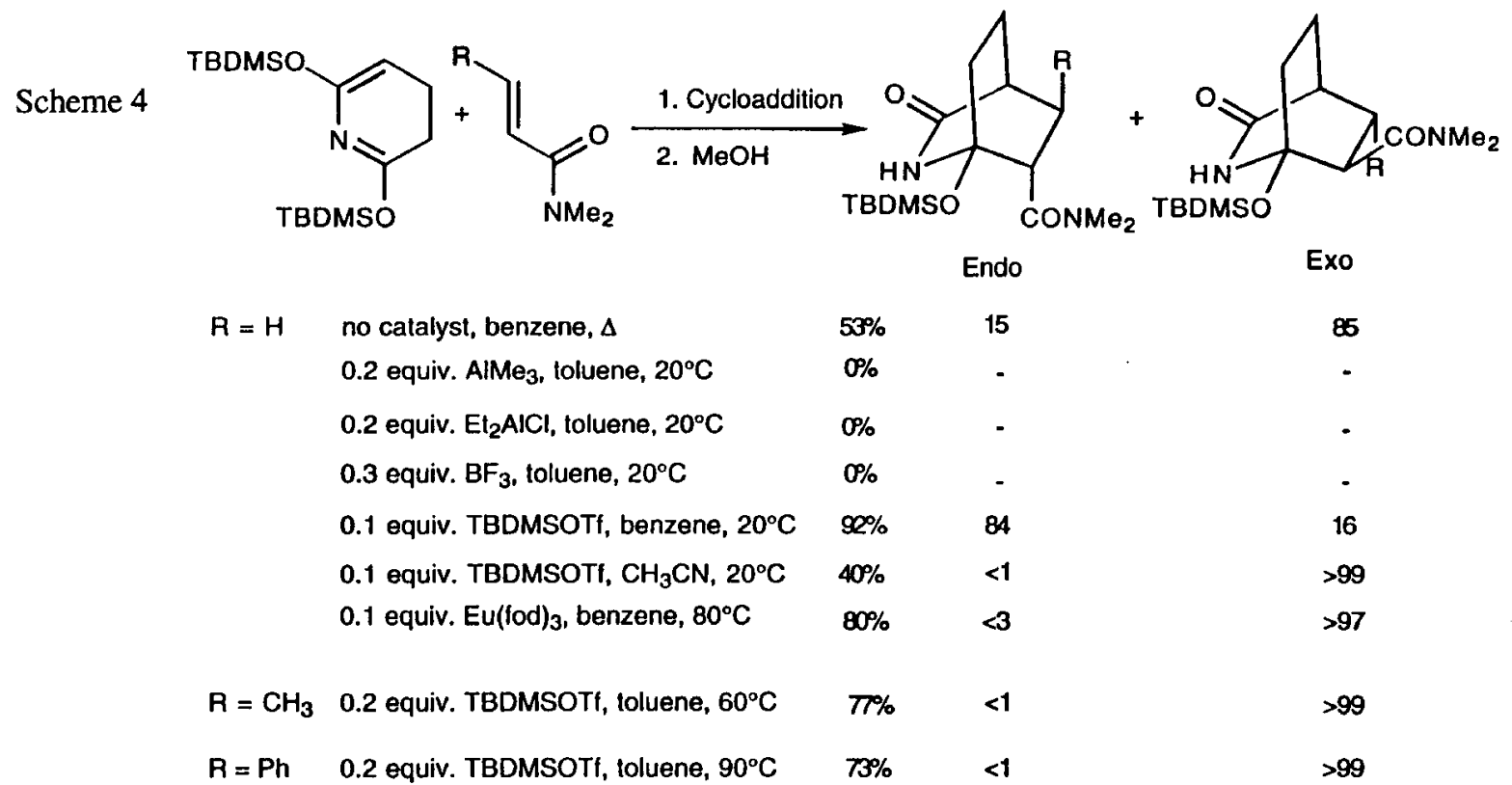

The best results were obtained from the combination of t-butyldimethylsilyl triflate with an $\alpha, \beta-$ unsaturated amide. The in situ generated iminium ion reacted as an excellent dienophile. 8 Furthermore, in benzene, with $\mathrm{N}, \mathrm{N}$ dimethylacrylamide, the expected reversal of exo to endo-selectivity was indeed observed.9 However the use of a more polar solvent or the presence of an additional substituent on the double bond gave an enhanced exo-selectivity. 6 This probably resulted from the higher polarity of the exotransition state. Also, when the reaction of the acrylic derivative was carried out with $\mathrm{Eu}(\mathrm{fod})_{3}$ as catalyst, the kinetic exo-selectivity was high.9 This remarkable influence of the nature of the Lewis acid catalyst on the endo-exo selectivity of the cycloaddition was also found with acyclic 2-azadienes. ${ }^{9}$ This observation is reminiscent of the remarkable influence of the nature of the acid catalyst on the stereochemistry of cycloaddition of silyloxydienes with aldehydes. 10

The pioneering work of Grieco's group had shown that lithium perchlorate in diethyl ether could exert a dramatic accelerating effect on organic reactions such as Diels-Alder cycloadditions. 11 The explosive character of dry lithium perchlorate led us to look for a safe alternative. We found that similar accelerating effects could be obtained with concentrated organic solutions of lithium trifluoromethanesulfonimide $\left(\right.$ LiNTf $\left._{2}\right)$. In addition we observed an influence of the counterion on the exo-selectivity of the reaction (Scheme 5). 12 
Scheme 5

TBDMSO

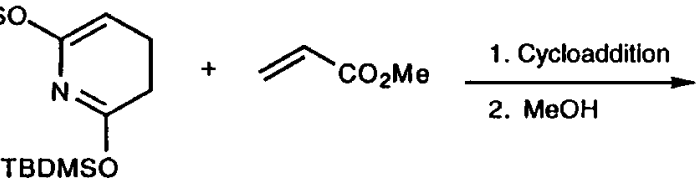

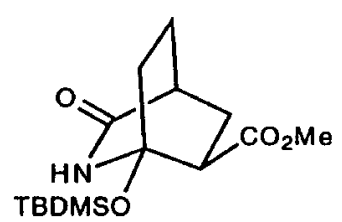

$$
\begin{gathered}
\text { EXO } \\
90 \%+10 \% \text { Endo } \\
>99 \%+- \\
75 \% \quad+25 \% \text { Endo }
\end{gathered}
$$

As a natural outcome of these studies on achiral amides, we decided to examine the reaction of 2azadienes with $\alpha, B$-unsaturated amides derived from non-racemic amines in the presence of TBDMSOTf or Eu(fod)3. In order to avoid the possibility of two reacting conformations, we selected a 2,5-disubstituted pyrrolidine possessing axial symmetry. Both exo- and facial selectivities of cycloaddition with cyclic and acyclic 2-azadienes were very high (Scheme 6).13,6

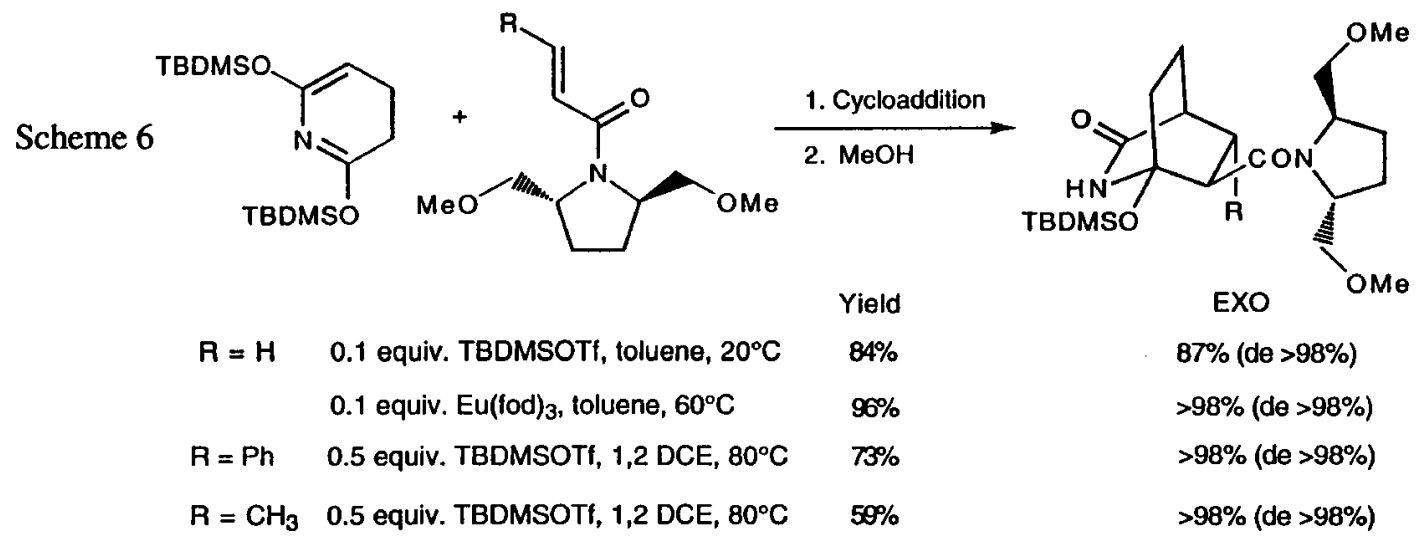

We have also examined Evans' and Oppolzer's dienophiles which have been successfully used in reactions with simple carbadienes. The results were rather disappointing. Evans' dienophile gave moderate yields of adducts and, when $\mathrm{R}=\mathrm{Me}$, the facial selectivity was lower than with the corresponding amide (Scheme 7).6

Scheme 7

TBDMSO<smiles>CCCCCOC1=CCCC(OCCCC)=N1</smiles><smiles>[2H]C=CC(=O)N1C(=O)O[C@@H](C)[C@H]1c1ccccc1</smiles>

$\stackrel{1.4 \text { equiv. Et } \mathrm{E}_{2} \mathrm{AlCl}}{\underset{\mathrm{CH}_{2} \mathrm{Cl}_{2},-78^{\circ} \mathrm{C}}{\longrightarrow}}$

$$
\begin{aligned}
& R=\operatorname{Me} 45 \%(\text { de } 80 \%) \\
& R=\operatorname{Ph~} 57 \%(\text { de }>98 \%)
\end{aligned}
$$

Surprisingly Oppolzer's dienophile derived from trans-crotonic acid gave an exo-adduct as a 1:1 mixture of diastereoisomers while the minor endo-adduct was formed in a highly stereoselective manner (Scheme 8). 6

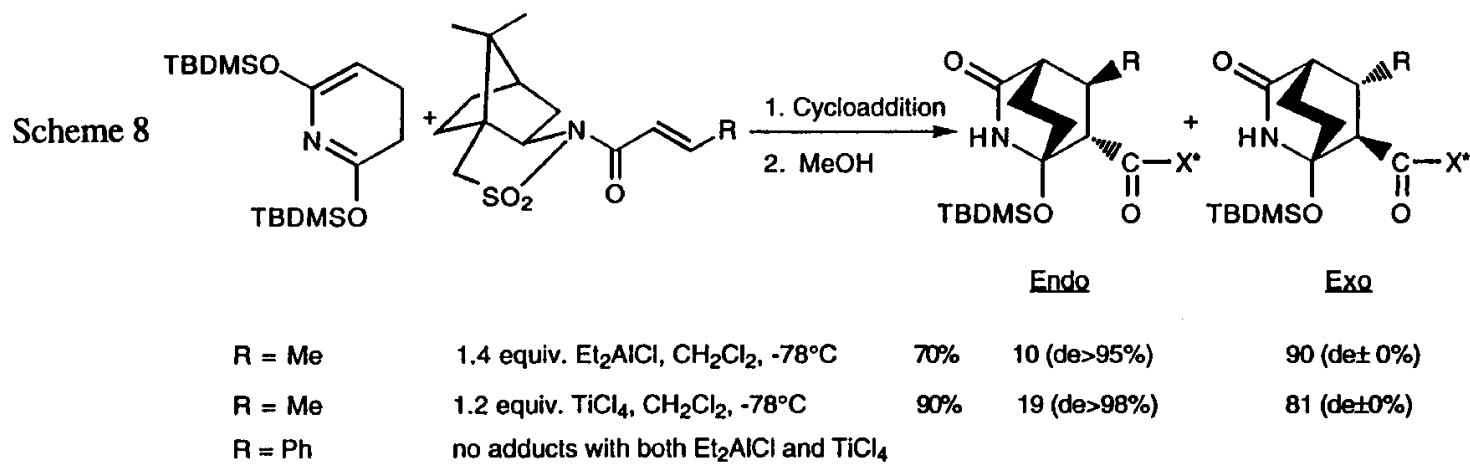


The dienophile derived from trans-crotonic acid did not yield any cycloadduct; only decomposition products were observed. These results underline the problems encountered with highly functionalized dienes which are easily decomposed by Lewis acids. Milder and preferably catalytic methods of activation are still needed to run efficiently Diels-Alder reactions with these highly sensitive dienes.

Our endeavours to develop a regio-, diastereo- and enantioselective methods of piperidine derivatives by a Diels-Alder strategy have thus been successful. It now remains to find a catalytic version of these asymmetric syntheses.

\section{Stereoselective cyclopentannulation of cyclic enones.}

The Robinson annulation which combines an enone (1,4-dipole equivalent) with a ketone (1,2-dipole equivalent) is one of the most important cyclocondensation reactions for the synthesis of six-membered rings (Scheme 9).

Scheme 9

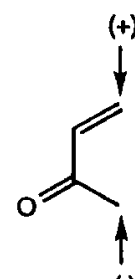

(-)<smiles></smiles>

catalyst<smiles>O=C1C=C2[CH][13CH][13CH2][C@H]2CC1</smiles>

Recently we became interested in developing an equivalent method for the synthesis of fivemembered rings. We decided to investigate the cyclocondensation of the 1,3-dipole equivalent 1 with cyclic enones (Scheme 10).

Scheme 10

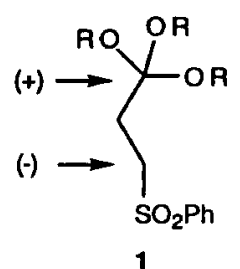<smiles>O=C1CC[C@H]([Hg])C1(O)[Hg]</smiles>

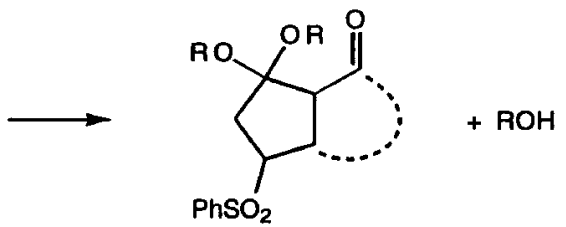

This novel annulation method of enones would generate a highly functionnalized five-membered ring. It should nicely complement Trost's palladium-catalysed cyclopentannulation ${ }^{14}$ in terms of scope and functionnalisation of the newly formed ring.

Earlier work had shown that highly selective 1,4-addition of $\alpha$-sulphonylcarbanions could be achieved in the presence of HMPA.15,16 These results could be easily reproduced using either HMPA or DMPU as cosolvent. On the other hand, the addition of catalytic amounts of $\mathrm{ZnCl}_{2}$-TMEDA 17 to an $\alpha$ sulphonyl Grignard reagent only gave the 1,2-adduct (Scheme 11).18

Scheme 11<smiles>O=C1C=CCCC1</smiles><smiles>O=C1C=CCCC1</smiles><smiles>[PH3+]=[Pt]</smiles>

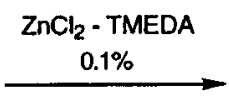

1. $\mathrm{ZnCl}_{2}-\mathrm{TMEDA}$

2. TMSCI-Et $\mathrm{I}_{3} \mathrm{~N}$<smiles>CCCC1CCCC(=O)C1</smiles>

85<smiles>COC1=CC(C(C)P(=O)(O)OC(C)=O)CCC1</smiles>

$\ll \%$<smiles>CCCC1(O)C=CCCC1</smiles>

15<smiles>COC1(C(C)S(=O)(=O)c2ccccc2)C=CCCC1</smiles>

$>98 \%$ 
We then developed a simple and practical one-pot method for the cyclopentannulation of cyclic enones (Scheme 12).

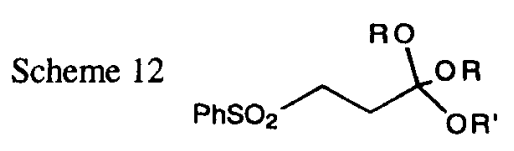

1. n-BULi-HMPA (DMPU)

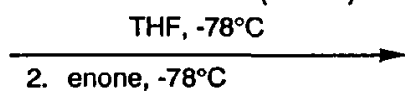

3. $\mathrm{TMSCl}, \mathrm{Et}_{3} \mathrm{~N}$

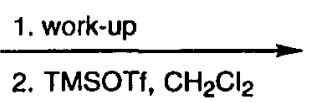

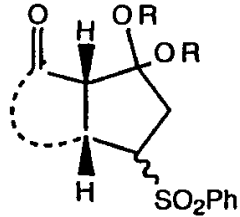

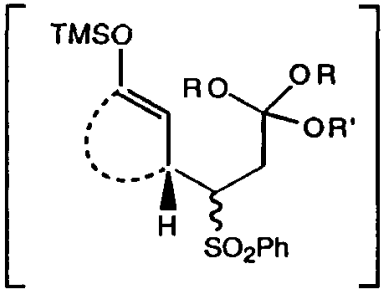

$\mathrm{A}=\mathrm{Me}, \mathrm{Et},-\left(\mathrm{CH}_{2}\right)_{2}$ $\mathrm{A}^{\prime}=\mathrm{Me}, \mathrm{Et}$

After generation of the carbanion with $\mathrm{n}-\mathrm{BuLi}$ in the presence of HMPA or DMPU, the enone was added followed by a mixture of trimethylsilyl chloride and triethylamine. Work-up with water to eliminate HMPA or DMPU was essential to the success of the cyclisation step which was best effected with trimethylsilyl triflate. Typical yields are shown in Scheme 13.18,19

Scheme 13
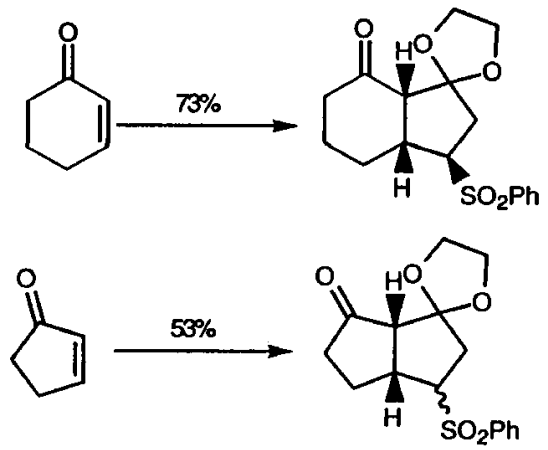<smiles>CC1=CCCC1=O</smiles>
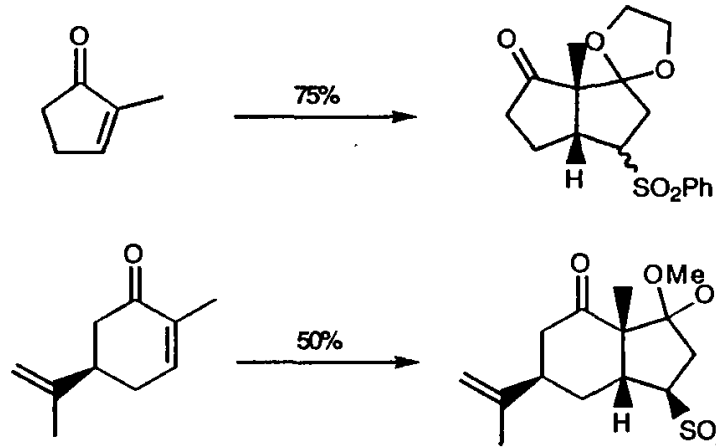

The new cyclopentannulation reaction tolerated substitution at $C_{2}, C_{4}$ and $C_{5}$ of the enone. Substitution at $\mathrm{C}_{3}$ slowed down the addition of the carbanion and, as a result, mainly led to enolisation of the ketone.

Interestingly the cyclopentannulation products could be easily transformed to produce a new enone as exemplified in Scheme 14.18

Scheme 14
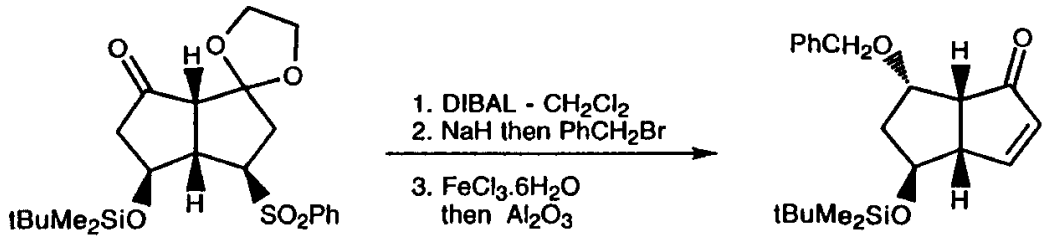

An asymmetric version of the reaction has been studied. In principle the chiral information could have been provided by the sulphur atom. However, our studies with chiral sulfoximines were unsuccessful : little diastereoselectivity was observed.20 A chiral sulphoxide-acetal was prepared but mainly yielded 1,2 adducts with enones. 20 This problem was recently solved by using a bulky Lewis acid (ATPH) 21 which complexes the carbonyl group of the enone. Thus the reaction of enantiomerically pure methyl p-tolylsulphoxide with cyclohexenone in the presence of 1.5 equivalents of ATPH yielded a 1,4adduct exclusively. However, the facial selectivity was still very low (Scheme 15). 
Scheme 15<smiles>O=C1C=CCCC1</smiles>

1. AlMe $_{3}$, 2,6-diphenylphenol, $\mathrm{CH}_{2} \mathrm{Cl}_{2}, \mathrm{RT}, 30 \mathrm{~min}$

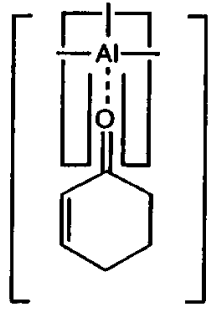

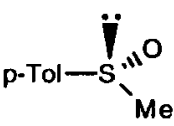

$(+)-(\mathrm{R})$<smiles>C#CC(C)C(C)C</smiles>

The most successful chiral auxiliary was a sulphonamide 2 derived from the chiral pyrrolidine derivative 3. The reagent was prepared from readily available starting materials (Scheme 16).22

Scheme 16<smiles>COC(C)(C)[C@H]1CCCN1</smiles>

3

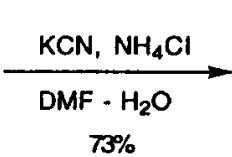

$73 \%$<smiles>O=C(OCCCl)O[Mg][Mg]</smiles>

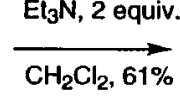<smiles>C=COS(=O)(=O)N1CCC[C@H]1C(C)(C)O</smiles>

de $: 10 \%$

Enantiomerically pure reagent 2 was reacted with various enones following the procedure described earlier for the corresponding sulphone. Cyclopentannulation products could be isolated and analysed by $\mathrm{X}$-ray diffraction analysis in the cases of cyclopentenone22 and 2-methylcyclohexenone23. Scheme 17 shows the sequence leading from a prochiral enone to a new enone of high enantiomeric purity.

These preliminary results demonstrate that we have succeeded in our endeavour to develop an efficient asymmetric cyclopentannulation method for enones. This practical route to enantiomerically pure cyclopentannulated products should find a number of useful applications. It uses cheap starting materials, proceeds with high selectivity and yields products which are useful intermediates.

\section{Scheme 17}
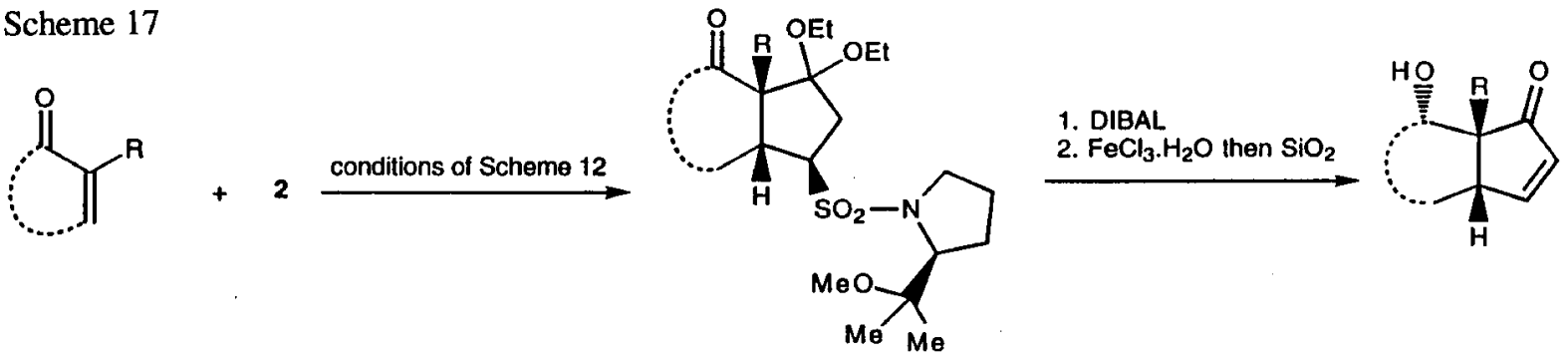<smiles>O=C1CCCC=C1C1CC[C@H]2C=CC(=O)C2[C@H]1O</smiles>

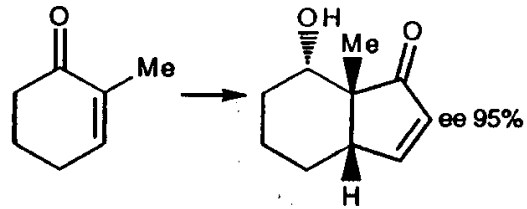<smiles>O=C1C=C2CCC(C1)C2</smiles> 


\section{Acknowledgements}

The content of this lecture was extracted from the Ph.D dissertations and postdoctoral work of a large number of excellent and enthusiastic coworkers : Dr P. Bayard, Prof. J.C. Carretero, Dr S. De Lombaert, Mr T. Delplanche, Dr M. Demillequand, Dr D. Giomi, Mrs C. Huart, Mr E. Jnoff, Dr M. Kapiamba, Dr T. Kimmel, Dr H. Lamy, Miss C. Mineur, Mr. O. Miserque, Dr I. Nemery, Dr P. Nshimyumukiza, Mr M. Renard, Dr M. Rivera, Dr B. Roekens and Dr F. Sainte. I thank them warmly. I also thank the Fonds National de la Recherche Scientifique, IRSIA and Ministère de l'Education et de la Recherche scientifique de la Communauté française de Belgique (Actions concertées 86/91-84 and 91/96-145) and the University of Louvain for generous financial support.

\section{References}

1. B.M. Trost Science 254, 1471 (1991).

2. L. Ghosez, Ph. Bayard, P. Nshimyumukiza, V. Gouverneur, F. Sainte, R. Beaudegnies, M. Rivera, A.M. Frisque-Hesbain and C. Wynants Tetrahedron 51, 11021 (1995).

3. F. Sainte, B. Serckx-Poncin, A.M. Frisque-Hesbain, L. Ghosez J. Amer. Chem. Soc. 104, 1428 (1982); L. Ghosez, B. Serckx-Poncin, M. Rivera, P. Bayard, F. Sainte, A. Demoulin, A.M. Hesbain-Frisque, A. Mockel, L. Munoz, C. Bernard-Henriet Lect. Heterocycl. Chem. 8, 69 (1985); P. Bayard, F. Sainte, R. Beaudegnies, L. Ghosez Tetrahedron Lett. 29, 3799 (1988); Ph. Bayard and L. Ghosez, 29, 6115 (1988).

4. M. Rivera, H. Lamy-Schelkens, F. Sainte, K. Mbiya and L. Ghosez Tetrahedron Lett. 29, 4578 (1988).

5. H. Lamy-Schelkens, Ph.D. Dissertation, University of Louvain, (1990).

6. K. Mbiya, Ph.D. Dissertation, University of Louvain, (1994).

7. M. Kakushima, D. Scott J. J. Can. Chem. 57, 1399 (1979); M. Kakushima J. Can. Chem. 57, 2564 (1979).

8. J.S. Baum, H.G. Viehe J. Org. Chem. 41, 183 (1976).

9. H. Lamy-Schelkens, D. Giomi and L. Ghosez Tetrahedron Lett. 30, 5887 (1989).

10. S. Danishefsky, E. Larson, D. Ashen, N. Kato J. Amer. Chem. Soc. 107, 1246 (1985).

11. P.A. Grieco, J.J. Nunes, M.D. Gaul J. Amer. Chem. Soc. 112, $4595-4596$ (1990); P.A. Grieco Aldrichimica Acta 24, 59 (1991); also see P.A. Grieco, Organic Chemistry in Lithium Perchlorate/Diethyl Ether in Organic Chemistry : Its Language and Its State of the Art p. 133, M.V. Kisakürek Ed., VCH, Basel (1993).

12. S.T. Handy, P.A. Grieco, C. Mineur and L. Ghosez Synlett 565 (1995).

13. H. Lamy-Schelkens and L. Ghosez Tetrahedron Lett. 30, 5891 (1989).

14. See for instance : B.M. Trost Angew. Chem. Int. Ed. Engl. 25, 1 (1986); B.M. Trost, S.M. Mignani, T.N. Nanniga J. Amer. Chem. Soc. 110, 1602 (1988); B.M. Trost, B. Yang, M. Miller J. Amer. Chem. Soc. 111, 6482 (1989); B.M. Trost, T.A. Grese J. Org. Chem. 57, 686 (1992); B.M. Trost, M.C. Matelich Synthesis 151 (1992)

15. M. Hirama Tetrahedron Lett. 22, 1905 (1981).

16. J. Nokami, T. Ohno, H. Kurihara, S. Wakabayashi Chem. Lett. 607 (1982).

17. J.F.G.A. Torssen, B.L. Feringa J. Org. Chem. 55, 4168 (1990).

18. M. Demillequand, Ph.D. Dissertation, University of Louvain (1993).

19. S. De Lombaert, I. Nemery, B. Roekens, J.C. Carretero, T. Kimmel and L. Ghosez Tetrahedron Lett. 27, 5099 (1986).

20. I. Nemery, Ph.D. Dissertation, University of Louvain (1991).

21. K. Maruoka, I. Shimada, H. Imoto, H. Yamamoto Synlett 519 (1994).

22. C. Huart, Ph.D. Dissertation, University of Louvain (1995).

23. B. Tinant, J.P. Declercq, C. Huart Acta Cryst. C51, 678 (1995). 